\title{
0 professor formador e o ensino de didática no curso de Geografia: a perspectiva dos alunos
}

\author{
The teacher educator and teaching of didactics in \\ geography licentiate course: the student perspective
}

El profesor formador y la enseñanza de la didáctica en la carrera de Geografía: la perspectiva de los alumnos

\section{Giseli Barreto da Cruz, Talita da Silva Campelo*}

Universidade Federal do Rio de Janeiro (UFRJ), Rio de Janeiro, RJ, Brasil

\section{Resumo}

O presente artigo toma como referência dados coletados para fins de uma pesquisa sobre a Didática e o aprendizado da docência no processo de constituição da identidade profissional de futuros professores, desenvolvida no período de 2012 a 2015. Tal pesquisa teve por objetivo analisar conhecimentos sobre a docência, construídos por meio do estudo de Didática, por futuros professores, assim como as consequências da disciplina Didática para o processo de constituição

GBC: Doutora em Educação, e-mail: giselicruz@ufrj.com.br

TSC: Doutoranda em Educação, e-mail: talitacampelo@gmail.com 
dos saberes profissionais docentes. Como estudantes do curso de licenciatura em Geografia avaliam a sua formação em Didática e o papel do professor formador no processo de aprendizagem da docência? Trata-se de um recorte de um estudo investigativo mais amplo, que abrangeu 14 cursos de licenciatura de uma universidade pública federal localizada no Estado do Rio de Janeiro. Como estratégia metodológica, optou-se pela aplicação de questionário e realização de grupos de discussão. A partir de pressupostos teóricos estruturados com base nos estudos de Roldão (2005, 2006), Shulman (1986), Gauthier (1998) e Cochran-Smith e Lytle (1999), buscou-se discutir os temas trabalhados em Didática, as formas de mediação do ensino predominantes nas aulas e o papel do professor formador no processo de constituição da base de conhecimento profissional docente. Os resultados apontam aulas de Didática muito mais centradas nos aspectos teóricos que acompanham o exercício docente, do que na própria docência em si, assim como a necessidade dos formadores, reconhecidos pelos licenciandos como referências de prática, incorporarem ao ensino que desenvolvem a própria prática como parâmetro de formação.

Palavras-chave: Formação de Professores. Professor Formador. Didática. Licenciatura em Geografia.

\begin{abstract}
The following article uses as reference the data collected within the research on Didactics and teacher learning in the constitution process of the professional indentity in future teachers, developed between the years of 2012 and 2015. Its objective is to analise knowledge about teaching constructed through the study of Didactics by future teachers, as well as the consequences of the subject matter of Didactics to the process of constitution of professional knowledge on teaching. How do students licentiating in Geography rate their education in Didactics and the role of the teacher educator in the process of learning to teach? This work is a fragment of a broader investigative study, which covered 14 licentiation programs in undergraduate level within a public federal university located in the state of Rio de Janeiro. As methodologic strategy, it was opted by applying survey and organized dicussing groups. From theoretical assumptions based on the studies of Roldão (2007, 2006), Shulman (1986), Gauthier (1998) and Cochran-Smith and Lytle (1999), it was discussed the themes worked in Didactics classes, the forms of teaching mediation predominant in classrooms and the role os the teacher educator
\end{abstract}


in the process of constitution of the teaching professional knowledge base. The results point to Didactics classes as much more centered on theoretical aspects that follow the practice of teaching, than the teaching itself, and that teacher educators, recognized by the students as references of practice, need to incorporate to the teaching they develop, the practice itself as a parameter of teaching.

Keywords: Teaching education. Teacher educator. Didactics. Licentiate in Geography.

\section{Resumen}

El presente artículo tiene como referencia los datos recogidos para una investigación sobre la Didáctica y el aprendizaje de la docencia en el proceso de constitución de la identidad profesional de futuros profesores, desarrollada en el período de 2012 a 2015. Esa investigación tuvo por objetivo analizar los conocimientos sobre la docencia construidos a través del estudio de Didáctica por futuros profesores, así como las consecuencias de la disciplina Didáctica para el proceso de constitución de los saberes profesionales docentes. ¿Cómo estudiantes de la carrera de profesorado en Geografía evalúan su formación en Didáctica y el papel del profesor formador en el proceso de aprendizaje de la docencia? Se trata de un recorte de un estudio investigativo más amplio, que abarcó 14 carreras de profesorado de una Universidad pública federal localizada en el Estado de Rio de Janeiro. Como estrategia metodológica, se optó por la aplicación de cuestionarios y la realización de grupos de discusión. A partir de presupuestos teóricos estructurados con base en los estudios de Roldão (2005, 2006), Shulman (1986), Gauthier (1998) y Cochran-Smith y Lytle (1999), se buscó discutir los temas trabajados en Didáctica, las formas de mediación de la enseñanza predominantes en las clases y el papel del profesor formador en el proceso de constitución de la base de conocimiento profesional docente. Los resultados apuntan clases de Didáctica mucho más centradas en los aspectos teóricos que acompañan el ejercicio docente, de lo que en la propia docencia en si, así como la necesidad de que los formadores, reconocidos por los licenciandos como referencias de práctica, incorporen la propia práctica a la enseñanza que desarrollan, como parámetro de formación.

Palabras clave: Formación de Profesores. Profesor Formador. Didáctica. Profesorado en Geografía. 


\section{Introdução}

Qual é a situação da formação inicial de professores nos cursos de Licenciaturas no Brasil atual? Que formação é oferecida aos futuros docentes em um contexto universitário? Com base em pesquisa de Gatti e Nunes (2009), referente ao projeto "Formação de professores para o ensino fundamental: instituições formadoras e seus currículos", observou-se uma formação decorrente de currículos fragmentados, com conteúdos excessivamente genéricos e com dissociação entre teoria e prática, estágios fictícios e avaliação precária, interna e externa. Nesse estudo, na análise das ementas das disciplinas de formação profissional (didáticas, metodologias e práticas de ensino, por exemplo) evidenciou-se que também predominam referenciais teóricos sem associação com práticas educativas e, na grande maioria dos cursos analisados, eles são abordados de forma panorâmica ou superficial. Verificou-se ainda que a escola, como instituição social e de ensino, é elemento quase ausente nas ementas, o que leva a pensar em uma formação de caráter mais abstrato e pouco integrado ao contexto concreto onde o profissional-professor vai atuar.

Ao assurmimos que recaem sobre a Didática estas críticas, emerge uma importante questão: afinal, o que se ensina na disciplina Didática? Que tipo de influências os professores formadores têm exercido nos licenciandos? O que acontece nas aulas de Didática tem sido referencial de boas práticas? Sendo a Didática a área de conhecimento que se ocupa com o processo de ensino-aprendizagem, estudos sobre o seu objeto contribuem especialmente para o permanente aperfeiçoamento das práticas de formação docente, no enfrentamento das denúncias que recaem sobre ela.

Propomos aqui uma discussão acerca da aprendizagem docente, por meio da análise do que prevalece como Didática no curso de licenciatura em Geografia, e quais contribuições o ensino de Didática tem proporcionado ao futuro professor visando a construção da sua prática profissional. 


\section{Aspectos teóricos e metodológicos}

Este trabalho tem como objetivo analisar conhecimentos sobre a docência construídos por meio do estudo de Didática por futuros professores, mais detidamente referente ao que faz o professor formador, em Didática, para ensinar a docência ao futuro professor.

Trata-se de um programa integrado de pesquisa, cuja fase inicial (2009-2012) objetivou analisar concepções e práticas didáticas de professores formadores que atuam com Didática nos cursos de licenciatura de três universidades do Estado do Rio de Janeiro (uma pública federal, uma pública estadual e uma privada), visando compreender como elas fundamentam o aprendizado da docência. Sendo nosso interesse a contribuição objetiva da Didática para a formação de professores oferecida pelos cursos de licenciatura, a segunda etapa da pesquisa em questão (2012-2015) voltou-se para o mapeamento da visão de alunos sobre sua formação.

Trataremos aqui da segunda etapa da citada pesquisa, que se deteve nos licenciandos da universidade que, das três investigadas na primeira fase, reúne há mais tempo o maior número de cursos de licenciaturas. Nosso campo empírico foram 14 cursos e nossos sujeitos cerca de 800 licenciandos. Foram considerados como sujeitos, alunos dos cursos de licenciatura da universidade federal que cursaram, até a altura do trabalho de campo, a disciplina Didática e também $70 \%$ das disciplinas que compõem a organização curricular de seus cursos.

No tocante ao embasamento teórico, construímos nosso referencial a partir das teorizações de Roldão (2005, 2006); Shulman (1986), Gauthier (1998) e Cochran-Smith e Lytle (1999). As contribuições desses autores constituem bases subsidiárias às nossas análises, a partir das seguintes formulações/questões:

1- Assumimos que o objeto da Didática, na sua perspectiva fundamental (CANDAU, 1983), é o processo de ensinar enquanto mediação e movimento de dupla transitividade (ROLDÃO, 2005). Desta forma, espera-se de um professor de Didática que, através de sua forma de mediação do ensino, seus alunos, futuros professores, reconheçam que ensinar 
requer uma variada e complexa constelação de saberes passíveis de diversas formalizações teórico-científicas, científico-didáticas e pedagógicas. Assim, na atividade docente há inúmeros fatores implicados, inclusive a forma como o professor compreende e analisa as suas práticas educativas, como articula diferentes saberes no seu ato de ensinar e como reflete na ação diante do inesperado e do desconhecido. Como este processo é percebido e, mais do que isto, compreendido, pelos alunos, futuros professores?

2- Entendendo que ensinar requer a estreita articulação entre os conhecimentos do conteúdo da matéria ensinada, o conhecimento pedagógico da matéria e o conhecimento curricular (SHULMAN, 1986), como se apresenta a base de conhecimento profissional do professor formador e como esta é percebida pelo seu aluno, futuro professor? Os saberes da prática pedagógica (GAUTHIER, 1998) são colocados em evidência, no contexto da mediação didática, para que os futuros docentes reconheçam sua pertinência e especificidade?

3- Reconhecemos que o conhecimento para a prática (COCHRAN-SMITH; LYTLE, 1999) é predominante na formação de professores. Porém, acreditamos que o conhecimento da prática pode contribuir mais eficazmente para o processo de constituição profissional docente. Como a formação em Didática pode favorecer o trânsito e a relação dialética entre os conhecimentos para, na e da prática, como caminhos subsidiários à prática docente?

Utilizamos como estratégia metodológica um questionário misto, aplicado através do SurveyMonkey, com questões abertas e fechadas, organizado em duas partes: perfil do estudante, com 19 questões, 16 delas obrigatórias; e o licenciando e a docência, esta parte subdividida em duas, sendo uma comum a todos os estudantes independente de seu curso, contendo cinco questões, das quais quatro eram obrigatórias, e a outra parte dedicada à especificidade de cada curso, com oito questões obrigatórias. O questionário garantiu total anonimato do respondente, permitindo-nos verificar, no tocante à identificação, apenas a quantidade de respondentes de cada curso. Tal instrumento foi escolhido devido ao quantitativo de alunos que poderiam ser alcançados na pesquisa (cerca de 1000 licenciandos). 
Neste trabalho, trataremos dos resultados da segunda fase da pesquisa, detendo-nos especificamente aos dados que se referem a perspectivas dos licenciandos sobre sua formação docente, especialmente em Didática. Aqui apresentamos a análise dos dados obtidos na segunda parte do questionário no que se refere à licenciatura em Geografia e, no contexto deste curso, nos propomos a discutir o que e como se ensina em Didática; e qual a contribuição da Didática para a aprendizagem da docência através da figura do professor formador.

\section{O ensino da didática no contexto da licenciatura em Geografia}

\section{Caracterização do curso e perfil dos estudantes}

O Departamento de Geografia da universidade participante deste estudo oferece cursos de licenciatura e bacharelado e o Programa de PósGraduação, mestrado e doutorado, além de cursos de extensão de curta duração. No ato da inscrição para ingresso (vestibular ou ENEM), o candidato deve fazer a opção para Licenciatura, pois as entradas para Licenciatura e Bacharelado são independentes. O atual currículo de Licenciatura em Geografia foi instituído em 2006, atendendo a Resolução CNE/CP 1, de 18 de fevereiro de 2002 e está estruturado em nove (9) semestres letivos.

O currículo da Licenciatura em Geografia oferece 33 disciplinas obrigatórias, quatro opções de disciplinas optativas de escolha restrita e 69 opções de disciplinas optativas de escolha condicionada. Ao analisar as ementas destas disciplinas, buscando aquelas que são de cunho estritamente pedagógico foram identificadas 13 disciplinas obrigatórias, três disciplinas optativas de escolha restrita e seis disciplinas optativas de escolha condicionada, ligadas a um projeto de extensão.

Quanto a esta última categoria, a $4^{\mathrm{a}}$. disciplina optativa se subdivide em cinco níveis e se refere à participação no Projeto de Extensão de Geografia, no qual os licenciandos podem colaborar na elaboração e/ou desenvolvimento de atividades que envolvam a divulgação na 
comunidade de estudos/temáticas produzidos na universidade através dos Laboratórios de Pesquisa. Pensando em grupos de estudo que investigam a docência de Geografia na Escola Básica, destaca-se o APEGEO Ateliê de Pesquisa e Práticas em Ensino de Geografia.

As disciplinas pedagógicas que são comuns às outras licenciaturas — Filosofia da Educação no Mundo Ocidental; Fundamentos Sociológicos da Educação; Educação Brasileira; Didática; Psicologia da Educação; Didática Específica, Prática de Ensino e Estágio Supervisionado I e II — são distribuídas ao longo de todo o curso. É necessário cursar a disciplina Didática como pré-requisito para Didática Específica, Prática de Ensino e Estágio Supervisionado I e II.

Os 44 participantes da pesquisa representando o curso de Geografia mostraram-se equilibrados em termos de gênero, com uma leve vantagem masculina (56,82\%). O público é composto basicamente por jovens solteiros (84,62\%), com média de idade de 19 a 24 anos $(79,54 \%)$. Um total de $70,45 \%$ estuda apenas a noite por conta das ofertas de disciplinas e por causa do trabalho. A maior parte deles convive com até três pessoas em casa $(33,33 \%)$ e são ajudados financeiramente pela família $(81,82 \%)$. A maior parte dos estudantes tem renda própria (91,71\%), sendo que deste total, $45,45 \%$ tem sua renda oriunda de alguma bolsa da universidade. Deste total, $48 \%$ trabalham para se sustentar ou para ser mais independentes, 38,10\% trabalham para ajudar a família e $23,81 \%$ para sustento da família. Dos licenciandos que trabalham, 31,82\% estão na área da educação seja como professores da escola básica ou particulares e em cursos pré-vestibulares ou de idiomas.

Os licenciandos estudaram em sua maioria sempre em escola particular (43,59\%), seguidos por $28,21 \%$ que sempre estudaram em escola pública municipal e/ou estadual, 17,95\% em ambas as redes e 10,26\% sempre em escolas federais. Com relação à escolaridade dos genitores, os dados apontam a maior parte dos pais com o Ensino Médio completo e Superior completo (40,91\%). O mesmo foi observado com as mães, mas com um aumento significativo no percentual (56,82\%). A ocupação profissional dos pais é bem diversificada. Entre os pais, as profissões mais 
citadas foram comerciante, rodoviário e servidor público, entre as mães dona de casa, comerciante e servidora pública.

Dos estudantes ouvidos na pesquisa, 84,09\% dos de Geografia querem ser professor. A maior parte dos estudantes baseia este desejo na admiração pela profissão e por professores com os quais estudaram, além da identificação com valores e potenciais humanitários e sociais que creditam à educação. O grupo que afirma não querer ser professor credita isso principalmente à baixa remuneração, condições de trabalho ruim, pouca valorização social e alguns deles pensam não ter características pessoais que consideram importantes nesse ofício.

\section{A Didática e a formação do professor em Geografia: o que e como se ensina em Didática?}

Dos licenciandos em Geografia ouvidos na pesquisa, 90,48\% cursaram a disciplina Didática; $42,86 \%$ Didática Específica, Prática de Ensino e Estágio Supervisionado I; e 28,57\% Didática Específica, Prática de Ensino e Estágio Supervisionado II. Interessa-nos a percepção desses licenciandos sobre a Didática e seu papel na formação docente. Nessa direção, nos cabe perguntar: qual é a visão dos participantes em relação às concepções e práticas didáticas predominantes no seu curso? O que faz o professor formador para ensinar a docência na perspectiva de seu aluno, o futuro professor?

Nos relatos sobre as aulas de Didática, falas, como a de GEO $8^{1}$, a qual afirma que "de todas as matérias de Educação, a Didática sem dúvida é a mais importante", endossam a ideia dos licenciandos em Geografia, que, em muitos momentos, usaram o mesmo termo importante para se referir a essas aulas. Para esses respondentes, as aulas de Didática possibilitam "a reflexão sobre métodos de ensino e práticas pedagógicas [...] e o pensamento crítico sobre

1 Para fins de preservação de identidade, conforme acordado no TCLE, os sujeitos serão identificados pela sigla GEO (iniciais do nome do curso), seguida do número do respondente. 
o papel do professor, sobre o currículo e a escola" (GEO 6). Para os alunos, sua contribuição se justifica porque estas disciplinas "auxiliam na transposição do conteúdo acadêmico para o escolar" (GEO 8). Entendendo, a partir das falas dos licenciandos em Geografia, que a Didática enquanto disciplina e objeto de estudo é importante para/na sua formação docente, queremos analisar o que prevalece como Didática nesse curso de formação de professores e suas contribuições para o processo de constituição profissional docente.

Os temas mais trabalhados na disciplina Didática podem ser organizados em torno de três eixos, a saber: i- conteúdos relacionados à construção do campo em seus aspectos políticos, sociais e históricos; ii- planejamento em seus diferentes níveis (curriculares e de ensino); iii- avaliação do processo de ensino-aprendizagem. No primeiro eixo, destacamos o estudo de Teorias Educacionais e o contexto sócio histórico, político, econômico e filosófico da prática pedagógica (71,43\%); no segundo eixo, Planejamento curricular e de ensino (57,14\%); no terceiro eixo, Avaliação de ensino (66,67\%).

Sobre a formação em Didática dos licenciandos em Geografia, os estudantes apontam como estratégias de ensino mais utilizadas pelos professores dessas disciplinas a leitura de textos - 85,71\% (com discussão temática com o texto ou sobre o conteúdo dele); seguida da prova 61,90\%; dos seminários e da exposição oral do professor - empatados em 52,38\%. É possível observar que o texto ocupa um papel preponderante na forma de o professor encaminhar a aula.

Dos temas estudados nas disciplinas de Didática, os licenciandos ouvidos consideram como indispensáveis para sua prática docente aqueles relacionados aos métodos e às técnicas de ensino (60\%), seguidos por planejamento curricular e de ensino respectivamente (40\%). Falas como a de GEO 7, que considera essenciais os temas que "envolvem conhecimento sobre matriz curricular, técnicas, planejamento", de GEO 6 e de GEO 20 que apontam o "desenvolvimento de práticas pedagógicas" como pontos-chave estudados nas aulas de Didática são representativas do interesse dos alunos em aprender o como ensinar e a identificação por parte deles frente a disciplina Didática - tanto Geral quanto Específica - como lugar para desenvolver esses conhecimentos para a prática. 
Para Cochran-Smith e Lytle (1999), implícita na relação de conhecimento para a prática está uma imagem de prática como sendo o como, quando e o que os professores fazem com a base de conhecimento formal no dia-a-dia da sala de aula. Incluídos aí estão a maneira pela qual os professores organizam as aulas e unidades de estudo, as atividades e materiais usados para cada grupo de estudantes, a sequência das matérias de uma disciplina, e o modo pelo qual se estruturam as aulas e as interações na sala, bem como os métodos de avaliação do progresso de cada turma. Quanto a isso, GEO 2 afirma ao falar de suas aulas de Didática que "eu acho positivo o modo como as aulas ensinam como 'se levar' uma aula".

Ainda nesta perspectiva, quando questionados sobre os aspectos positivos e/ou negativos das aulas de Didática, os licenciandos destacaram como pontos favoráveis justamente a aprendizagem de métodos e técnicas de ensino (67\%). Também citaram a relação professor-aluno, a exposição do professor de suas experiências na docência, a escolha dos textos, as avaliações e a apresentação dos principais teóricos da educação como se observa na fala a seguir: "Estudamos os principais teóricos no assunto e então nos abriu um leque de possibilidades de meios e formas as quais podemos trabalhar em sala de aula" (GEO 18).

Quando a questão se volta para a Didática Específica de Geografia, os alunos destacam como pontos positivos as experiências de campo, a contextualização delas nas aulas, a oportunidade de conhecer diversos espaços de ensino in/formal, a apropriação da transposição didática e o contato com diversos recursos que podem ser usados pelo professor. Isso se evidencia nos relatos que se seguem:

Melhor interação com a disciplina, crítica sobre o papel do professor, sobre o currículo e a escola (GEO 6);

Transmitia a rica didática geográfica como algo simples e importantíssimo, por mais que o assunto seja considerado complicado/difícil (GEO 14);

Conhecemos todo o processo de construção do livro didático [...], houve uma constante troca entre o que aprendíamos na universidade e o cotidiano que 
encontrávamos no estágio obrigatório, os textos trabalhados em sala buscavam [incentivavam] sempre uma auto reflexão sobre nosso papel enquanto professor e nossas práticas, obtivemos uma visão da Geografia não só como professores [...], palestras com professores do ensino básico [...], pudemos conhecer diferentes escolas [...] museus [...] tivemos trabalhos de campo que enriqueceram nossa aprendizagem (GEO 18).

É importante perceber também que, aparentemente, os alunos fazem confusão entre os objetivos das disciplinas de Didática e os de Didática Específica. Nota-se isso quando os alunos citam como ponto negativo da Didática o fato de ter alunos de outros cursos nas turmas e do assunto não se restringir à Geografia. Sobre isso, GEO 17 relata que "a matéria não teve enfoque para minha área em específico, visto que havia muitas pessoas em sala de vários cursos diferentes".

A partir dos apontamentos dos licenciandos em Geografia sobre os pontos positivos e negativos das aulas de Didática Específica, incluindo Prática de Ensino e Estágio Supervisionado I e II, fica claro que os alunos querem aprender nestas disciplinas sobre os saberes e fazeres da docência, a partir da própria prática docente em si, conectando os conhecimentos acadêmicos e os conhecimentos da prática docente de uma maneira que supere a desconexão entre escola e universidade. Também fica claro que isto não implica necessariamente em uma supervalorização da prática em detrimento da teoria, seja dos conhecimentos científicos pedagógicos ou da disciplina em si - no caso, Geografia, mas, sim, em uma interseção, baseada no ensino, entre eles.

Isso incide em uma formação docente que favoreça o desenvolvimento do conhecimento pedagógico, um conjunto de formas alternativas de representação que encontram origem tanto na pesquisa como nos saberes oriundos da prática docente. Assim, esse conhecimento base para a docência vai, além do conhecimento da disciplina por si mesma, para uma dimensão do conhecimento da disciplina para o ensino.

Para Shulman (1986), a chave para distinguir o conhecimento pedagógico repousa na interseção de conteúdos diversos e os da pedagogia, na 
capacidade que um professor tem de transformar o conhecimento do conteúdo que ele possui em formas que sejam pedagogicamente eficazes e possíveis de adaptação às variações de habilidade e contexto apresentados pelos alunos.

Isso se relaciona com o conhecimento didático do conteúdo por este consistir nos modos de formular e apresentar o conteúdo de modo a torná-lo compreensível aos alunos, incluindo analogias, ilustrações, exemplos, explanações e demonstrações. A ênfase está nas maneiras de se representar e reformular o conteúdo de tal forma que ele se torne compreensivo aos alunos.

Para Shulman (2005), este é também o conhecimento que se refere à compreensão docente do que facilita ou dificulta o aprendizado discente de um conteúdo em específico. Assim, o conhecimento didático do conteúdo também inclui o entendimento do que torna fácil ou difícil a aprendizagem de determinado tópico, bem como as concepções errôneas dos estudantes e suas implicações na aprendizagem.

Tanto o conhecimento pedagógico quanto o conhecimento didático do conteúdo são conhecimentos base para a docência que precisam de muito investimento na formação inicial. Pensando no ensino, enquanto mediação e movimento de dupla transitividade, como característica distintiva da docência e, portanto, potente norteador das práticas formativas de professores (ROLDÃO, 2005, 2006), não é de se estranhar o desejo dos licenciandos em Geografia de mais espaços para se pensar sobre/ para o ensino nas aulas de Didática. Isso se torna latente quando relatam que sentem necessidade de estudar sobre as especificidades do ensino de Geografia também na Didática. No entanto, isso nos leva a pensar sobre o que se tem de fato prevalecido nessas aulas.

\section{O professor formador e a aprendizagem da docência: qual a contribuição da didática?}

A maior parte dos licenciandos $(76,19 \%)$ reconhece que a forma como seus professores ensina os ajuda a pensar sobre sua futura prática 
docente. Para os estudantes, o favorecimento, durante as aulas, de reflexão e problematização sobre a realidade escolar, o currículo, os diversos recursos que podem ser usados em sala de aula, bem como sobre os métodos e técnicas de ensino, é determinante para que o professor seja referencial de formação. Destacam também a importância da experiência anterior do professor na escola básica.

Esse aspecto, que comunga sentimentos tão antagônicos, explicita algumas contradições. Nesse caso, os licenciandos de Geografia foram muito críticos quanto aos seus formadores, mas ao falarem da influência deles revelaram majoritariamente aspectos positivos das práticas de seus professores. Esse resultado exige-nos problematizar como o saber da ação pedagógica (GAUTHIER, 1998) vem se elaborando e se dando a conhecer através dos formadores quando ensinam.

Para nossos investigados, a forma como o professor de Didática ensina, de acordo com o que afirma GEO 6, "ajuda a refletir e criar novas possibilidades para nossa própria prática docente”. Para GEO 4, isto acontece quando/porque esses professores "utilizam formas que nos fazem pensar como responder as futuras dúvidas dos meus futuros alunos. Dessa forma, nos faz exercitar a prática docente". GEO 7 afirma que "a partir do posicionamento do professor em sala posso repensar como agir se fosse eu na situação".

Nesse sentido, para os alunos, tão importante quanto conhecer os fundamentos das ciências da educação, dominar conhecimentos pedagógicos e de conteúdo, é refletir e problematizar de forma provocativa sobre o cotidiano e a cultura escolar. Os licenciandos reconhecem que isto deve ser feito de modo especial nas aulas de Didática e valorizam quando seus formadores mostram "diferentes pontos de vista da profissão, além de diversos meios de lecionar" (GEO 8), e os ajudam a "ter uma visão crítica sobre o ambiente escolar, os conteúdos e em relação aos materiais didáticos" (GEO 19).

Para eles, isso se dá pela própria experiência docente desses formadores e se potencializa quando os professores formadores também tem experiência na docência na escola básica. Para GEO 9, só o fato de seus professores formadores serem "pessoas que já estão lá, lecionando" é 
referencial na medida em que "a experiência deles conta muito" (GEO 21). Assim, consideram aspectos relevantes "as vivências que o professor nos passa" (GEO 1), porque desses relatos conseguem esclarecer "todos os pontos didáticos essenciais" (GEO 14).

Os licenciandos em Geografia projetam no professor de Didática o formador responsável por fazer a conexão entre o que ensinar, para quem ensinar, por que ensinar e como ensinar. GEO 18 sintetiza esta ideia quando defende que a prática de seus professores formadores é constitutiva de sua futura prática docente porque/quando eles "utilizavam vários recursos didáticos diferentes, textos de autores com diferentes visões, ferramentas que aproximavam teoria e realidade e avaliações construtivistas. Assim, a própria aula de Didática nos oferecia modelos variados de metodologias e nos fazia refletir sobre nossa prática como docente".

É importante perceber que os licenciandos em Geografia têm clareza da necessidade do professor saber os fundamentos (conhecimentos) da sua área de atuação. Para Gauthier (1998, p. 31), este seria o saber das ciências da educação, que consiste em um saber profissional específico que não está diretamente relacionado com a ação pedagógica, mas permeia a maneira do professor existir profissionalmente.

No entanto, ainda que considerem essencial o conhecimento teórico desenvolvido nas aulas de Didática, os licenciandos em Geografia denunciam que a desconexão dos temas abordados com a realidade escolar tem sido um ponto negativo nas aulas. Sobre isso, GEO 10 afirma que "às vezes, é muita teoria e pouca reflexão sobre a prática que acontece nas salas de aula".

Essa dicotomia criada entre conhecimentos acadêmicos e conhecimentos oriundos da prática docente há muito já tem sido denunciada como um dos grandes entraves para a formação de professores (COCHRAN-SMITH; LYTLE, 1999; GATTI, 2010, 2013; ROLDÃO, 2006; ZEICHNER, 2010). Para Roldão (2005, p. 37), as diversas especificações da docência não residem nesta lógica de alternância - pedagógico ou científico - mas sim na sólida construção de um saber científico-profissional integrador de todos os saberes que se mobilizam para a prática da ação de ensinar enquanto fazer aprender alguma coisa a alguém. 
Esta problemática ganha novos tons quando lançamos o olhar para os professores formadores. Para muitos dos licenciandos em Geografia, a desconexão não está somente na distância entre o que se ensina na universidade e que se vive na escola, mas também na contradição da prática dos seus professores formadores. GEO 9 e GEO 21 afirmam respectivamente que "a maioria das aulas pouco servem na prática. Alguns dos professores refletem exatamente o que eles criticam" e que "alguns professores de Didática e seus discursos estão muito distantes da realidade de sala de aula".

Ainda sobre os pontos desfavoráveis das aulas de Didática, além da desconexão dos temas abordados com a realidade escolar e o distanciamento entre "o que se ensina" e o "como se ensina" por parte de alguns professores, os alunos também apontam a extensa carga de conteúdo, discursos retóricos mais do que teóricos, debates com pouca preocupação em se pensar proposições práticas e a pouca participação dos alunos nas aulas. A seguir, algumas falas subsidiárias dessas constatações:

Falta de trabalhos que nos instiguem a criatividade diante dos problemas que surgem nas salas de aula (GEO 11);

Grandes possibilidades de debates e problematizações sem alguma [nenhuma] resposta (ouvi sempre 'aí cabe a você pensar em uma solução') (GEO 17);

Não podemos [os alunos] contribuir por meio de troca de experiências em sala de aula já que a disciplina é ofertada antes da prática de ensino (GEO 18);

É uma disciplina que tenta sozinha abarcar assuntos que deveriam ser abordados em disciplinas obrigatórias específicas (GEO 7).

Como se pode depreender, as escolhas do professor formador para ensinar Didática e, nessa direção, favorecer o aprendizado da docência, são decisivas para a afirmação do papel da Didática na formação de professores. 


\section{Considerações finais}

O campo da Didática enfrenta ainda hoje, passados mais de 30 anos, o desafio proposto por Candau (1983) de uma Didática fundamental como meio de superação de uma Didática instrumental. Na tentativa de superar uma didática essencialmente prescritiva e fazer valer o fundamental da Didática na formação docente, o ensino de Didática sofreu várias transformações, desde a mudança do nome da disciplina, diminuição de sua carga horária e abordagem de diversos temas relacionados ao ofício docente.

Concluímos que na licenciatura em Geografia prevalece a tendência de tratamento de diversos temas necessários à formação de professores, sem, no entanto, se manifestar a preocupação com a multidimensionalidade da Didática, expressa na estreita articulação entre o político social, o humano relacional e a técnica (CRUZ et al., 2014; CRUZ; ANDRÉ, 2014).

As concepções que prevalecem no ensino de Didática na licenciatura em Geografia são as ligadas tanto a ideia de professar um saber, quanto a de diálogo em torno do conhecimento - dupla transitividade. Nota-se que ambos estão presentes nas aulas de Didática, com maior ou menor ênfase de acordo com o docente. Os dados evidenciam aulas de Didática muito mais centradas nos aspectos teóricos que acompanham o exercício docente, do que na própria docência em si. Para os licenciandos ouvidos, suas aulas de Didática são em boa parte descontextualizadas da realidade escolar, bem como dos saberes que emergem da prática docente. Isso é preocupante quando tratamos de Didática e especialmente grave quando tratamos das Didáticas específicas, que envolvem o estágio supervisionado e a prática de ensino.

Nesse sentido, os licenciandos em Geografia creditam ao professor de Didática o papel de conectar os conhecimentos acadêmicos e os oriundos da prática docente, não se limitando a conexão dos temas abordados nas aulas com a realidade escolar, mas principalmente superando o distanciamento entre o que se ensina e o "como se ensina". Para esses 
licenciandos, a forma como seus professores de Didática ensinam é tão importante quanto o conteúdo que está sendo trabalhado.

Reconhecem-se, assim, sob forte influência de seus formadores, e indicam ter clareza que refletirão em suas práticas futuras o que aprenderam sobre docência ao verem seus professores de Didática dando aula. No entanto, isso se dá a despeito da qualidade que atribuem à essas práticas. A maior parte dos respondentes se afiliou a ideia de que a influência do formador está tanto no que se quer ou não replicar: um modelo para o bem ou para o mal, mesmo que seja no sentido de "nunca fazer isso".

A opinião dos respondentes sobre as práticas de seus formadores demonstra uma grande insatisfação com o que tem acontecido nas aulas de Didática. Isto nos permite levantar duas hipóteses: as "boas" práticas dos formadores são escassas ou as práticas "ruins" são "tão ruins" que prevalecem no imaginário sobre qualquer prática que seja "boa” ainda que estas últimas sejam em maior quantidade. Essa hipótese parece se adequar melhor a situação, inclusive diante das incongruências constatadas: os licenciandos de Geografia valorizam a disciplina didática; consideram importante os conteúdos e temas que nela são tratados; e reconhecem muitos aspectos positivos nessas aulas; mas, quando analisam a disciplina como um todo, não sentem que suas espectativas sobre o aprender a docência estão sendo plenamente atendidas.

A fragilidade da formação docente do Brasil está clara e acreditamos que para além da necessidade de reformulações estruturais e curriculares mais amplas, a Didática tem potencial para contribuir hoje na superação de pelo menos dois dos mais graves problemas das licenciaturas: a desconexão entre escola e universidade; e a falta de diálogo entre as dimensões teórica, técnica, humana e política da formação de professores.

No entanto, nos preocupa observar que mesmo com tantos avanços em relação à Didática enquanto campo de produção de conhecimento sobre o processo ensino-aprendizagem, disciplina de formação de professores e prática pedagógica, isto não se traduziu efetivamente nas aulas de Didática nos cursos de licenciatura. Reconhecemos os bons exemplos apontados pelos próprios sujeitos desta pesquisa, mas entendemos 
que enquanto eles se reduzirem a iniciativas isoladas e marcadas por investimentos pessoais de alguns professores, a Didática vai se distanciar cada vez mais do desafio de ensinar a docência, não como mera aplicação de técnicas e sim entendendo o ensinar como um ato político, transformador e comprometido com o contexto social. Se os futuros professores não aprenderem isso nas aulas de Didática, onde aprenderão? Se os professores de Didática tratarem essa perspectiva de ensino apenas teoricamente, que pressupostos práticos ensinarão aos licenciandos?

\section{Referências}

CANDAU, V. (Org.). A didática em questão. Petrópolis: Vozes, 1983.

COCHRAN-SMITH, M.; LYTLE, S. L. Relationships of knowledge and practice: teacher learning in communities. Review of Research in Education, v. 24, p. 249305, 1999.

CRUZ, G. B.; OliVeIRA, A. T. C. C.; NASCIMENTO, M. G. C. A.; NOGUEIRA, M. A. Ensino de Didática: entre recorrentes e urgentes questões. Rio de Janeiro: FAPERJ/Quartet Editora, 2014.

CRUZ, G. B.; ANDRÉ, M. E. D. A. Ensino de didática: um estudo sobre concepções e práticas de professores formadores. Educação em Revista, v. 30, n. 4, p. 181-203, out./dez. 2014.

GATTI, B. A.; NUNES, M. (Org). Formação de professores para o ensino fundamental: estudo de currículo das licenciaturas em pedagogia, língua portuguesa, matemática e ciências biológicas. São Paulo: FCC/DPE, 2009. (Textos FCC, n. 29).

GATTI, B. A. Formação de professores no Brasil: Características e problemas. Educação e Sociedade, v. 31, n. 113, p. 1355-1379, out./dez. 2010.

GATTI, B. A. Educação, escola e formação de professores: políticas e impasses. Educar em Revista, n. 50, p. 51-67, out./dez. 2013. 
GAUTHIER, C. et al. Por uma teoria da pedagogia: pesquisas contemporâneas sobre o saber docente. Ijuí: Editora Unijuí, 1998.

ROLDÃO, M. C. Formar para a excelência profissional: pressupostos e rupturas nos níveis iniciais da docência. In: Simpósio nacional de educação básica: pré-escolar e $1^{\circ}$ ciclo - FORMAÇÃO DE PROFESSORES E EDUCADORES DE INFÂNCIA: QUESTÕES DO PRESENTE E PERSPECTIVAS FUTURAS, 1., 2003, Aveiro. Anais... Aveiro: Universidade de Aveiro, 2005. 1 CD-ROM.

ROLDÃO, M. C. A formação de professores como objecto de pesquisa: contributos para a construção do campo de estudo a partir de pesquisas portuguesas. Revista Eletrônica de Educação, v. 1, n. 1, p. 50-118, set. 2007.

SHULMAN, L. S. Conocimiento y enseñanza: fundamentos de la nueva reforma. Profesorado: Revista de curriculum y formación del profesorado, v. 9, n. 2, p. 1-30, 2005.

SHULMAN, L. S. Paradigms and research programs in the study of teaching: a contemporary perspective. In: WITTROCK, M. C. (Ed.). Handbook of research on teaching. 3 ed. New York: Macmillan, 1986. p. 3-36.

ZEICHNER, K. Repensando as conexões entre a formação na universidade e as experiências de campo na formação de professores em faculdades e universidades. Revista Educação, v. 35, n. 3, p. 479-504, set./dez. 2010.

Recebido: 11/06/2016

Received: 06/11/2016

Aprovado: 30/09/2016

Approved: 09/30/2016 